\title{
XIII. Essay on the franklinian theory of electricity. Read before the Askesian Society in the Session 1802-3
}

\section{Samuel Woods Esq.}

To cite this article: Samuel Woods Esq. (1803) XIII. Essay on the franklinian theory of electricity. Read before the Askesian Society in the Session 1802-3, Philosophical Magazine Series 1, 17:66, 97-113, DOI: 10.1080/14786440308676378

To link to this article: http://dx.doi.org/10.1080/14786440308676378

Published online: 18 May 2009.

Submit your article to this journal $\pi$

山 Article views: 2

View related articles $\sqsubset$ 
XIII. Essay on the Franklinian Theory of Electricity. By Samuex Woods, Esq. Read before the Askesian Society in the Session 1802-3.* $T_{\text {HE science of electricity offers an extensive and interest- }}$ THE science of electricity offers an extensive and interesting field of inquiry to the curious and speculative mind: the diligence of observation and experiment has collected an almost unlimited variety of facts, which it is often difficult to refer by any perspicuous classification to a few simple and general principles; and notwithstanding the endeavours of philosophers well qualified by their situation, talents and pursuits, to examine the effects, ascertain the properties, and investigate the laws of this singular fluid, it is still an arduous task to discover the connecting links which unite the numerous phænomena in one luminous and consistent system. Those striking appearances which arrest attention and create astonishment, are perhaps less calculated to convey substantial information than an accurate and repeated scrutiny into the minuter effects and operations. The recent and surprising discoveries in Galvanic electricity may convince us that our knowledge hardly penctrates beneath the surface. We know, indeed, that by rubbing a piece of glass or sealing-wax particular signs and actions are produced, which may be communicated to, and in certain circumstances retained by, other bodies: and we impute these signs and actions to the influence of a peculiar fuid, which we denominate electricity. But we are yet unable to conceive the reason or the means by which friction generates this power, or how its passage is obstructed or impeded by some particular substances : vapours, clouds, fogs, rain, and even the atmosphere, almost universally and uniformly indicate, when examined by delicate instruments, the presence of electricity; and though it is reasonable to conclude its agency of great extent and importance in our system, we are still ignorant what office is assigned to this subtile fluid in the ceconomy of nature.

It has justly been observed that the effects of electricity are in many instances strictly mechanical, producing local motion like gravitation, and therefore a proper subject of mathematical investigation. The establishment of electrical science on such principles has been attempted by several : in the opinion of the ingenious editor of the Supplement

* Copied by permission from the records of the society.

Vox. XVII. No.66. G

to

Novemler 1803. 
to the Encyclopædia Britannica, Mr. Aepinus and his fols lowers, Messrs. Cavendish and Coulomb, have framed a perspicuous and demonstrable theory. The work of $\mathrm{Ep}_{\mathrm{pi}}$ nus I have not yet been able to procure; but, perhaps, at some future period I may be tempted to offer to the society a general view of the Apinian theory, combined with the illustrations of his disciples.

I have undertaken on the present occasion to exhibit a succinct but, 1 trust, an intelligible view of that theory, respecting the operations of the electric fluid, which ascribes all electrical phænomena to the passage of this fluid from one body to another, disturbing from various causes that equilibrium which it is the constant tendency of nature to preserve, producing an increase or diminution of quantity, and a consequent effort to recover its original state: a theory which, though not originating with Dr. Franklin, owes its present adoption and celebrity to the discoveries and illustrations of that ingenious electrician. The redundancy and deficiency of the electric fluid form the comer stone of Dr. Franklin's theory; and the greatest part of what has been since added is a more distinct explanation of the mode of action by which such redundancy and deficiency produce the observed phænomena. I shall waive for the present any examination into the nature of electricity in the abstract, and assume its materiality as a subtile and most commonly an invisible fluid, which, in certain cases, becomes obrious to our senses; sometimes amusing us by the singularity of its action; at other times, by its stupendous effects, evincing itself one of the most powerful agents in nature.

In order to place the advantages and defects of this theory in the most perspicuous point of vicw, I shall endeavour to arrange the subject under a few general heads or propositions; by which means we shall be euabled to examine with more facility the dependence and connection of these propositions with each other, and the degree of proof by which they are individually and unitedly supported: but before we enter more particularly upon this examination it will be proper to premise a few observations respecting the terms in common use.

The term electricity is used too ofter in a vague and indefinite sense, sometimes for the fluid or cause of action, and at others for its perceptible effects : there is no single word yet introduced which bears the same relation to electricity as caloric to beat; and it appears, at present, most 
philosophical to apply the electric fluid as the cause or power, and electricity to the effect.

Electricity is found to be of two kinds : one produced by the excitation of glass, and formerly called vitreous : the other by the excitation of resin, and called resinous :whether we impute these different phenomena to the action of one or of two fluids, it is convenient to adopt sothe terms which shall distinguish these different states, if of one fluid; or the different fluids if two : as a mean of such distinction, the terms positive and negative may be safely acquiesced in by all parties, without any precise definition of the sense in which they ought to be received. The adherents of Dr. Franklin consider positive as denoting redundancy,-and negative, deficiency.

When electrical appearances, viz: the attraction of light bodies or sparks, are induced by friction upon any body, such body is said to be excited.

Electricity may be prodiced four ways :-1. Friction; 2 . Heating and cooling, as is particularly remarkable in the tourmalin; 3. Melting, or pouring one melted substance into ariother ; 4. Evaporation : perhaps all these modes may be justly deemed mectianical, and resolve themselves into friction: When electricity is communicated from an excited electric to another body, that body is said to be electrified. I shall first state the series of propositions which I conceive comprises the most prominent and leading features of the Franklinian theory; and sball then consider them separately, adverting to the proofs by which they are supported.

Prop. 1. That the phænomena of electricity are imputable to the operations of one fluid, peculiar in its nature and properties ; generally invisible; extremely subtile and elastic; universally and plentifully diffused through the atmosphere and other terrestrial substances.

Prop. 2: That the particles of which this fluid is com. posed have a strong attraction to other matter, and a strong repulsion betwcen themselves.

Prop. 3: That this fluid, pursuant to the general law of hydrostatics, will, in a state of rest, be uniforinly diffused in proportion to the capacity of bodies, and in this state 0 uniform distribution will produce no effect cognizable by our senses; but that this state of equilibrium is frequently, and may easily be, disturbed by natural or artificial causes.

Prop. 4. That this fluid moves with various degrees of facility through the pores of different kinds of matter in a certain class of bodies which are capable of transmitting this-fiuid with facility, and for that reason called conduc- 
tors, such as metals, water, \&c., it moves without any perceivable obstruction; but that in another class denominated clectrics, such as glass, sealing-wax, \&xc. which on friction produce signs of electricity, it either moves with extreme difficulty, or is entirely immoveable.

Prop. 5. That though electrics are subdivided into two classes :-1. Glass, 8ce. which on excitation have a general tendency to emit the electric fluid by disturbing the equilibrium, collecting it, by means of the rubber, from the surrounding bodies and conveying it to some other body, producing the negative or minus state in those bodies, and the positive or plus state in the body to which it is so conveyed : 2. Resin, sulphur, \&c. whose effects are precisely the reverse of the other class, having a general tendency on excitation to receive the electric fluid from any body with which it is immediately connected, producing a negative state in that body, and, by transmission through the rubber, a positive state in the surrounding bodies-yet that this affords no presumption of the existence of more than a single fluid.

Prop. 6. That any excited electric is capable of communicating, by contact with other bodies, an clectricity similar to its own; and by proximity without contact, of inducing an opposite state of electricity without losing any part of its own possessions.

Prop. 7. That the two different states of positive and negative electricity may be easily and universally distinguished from each other by certain constant and invariable indications.

Prop. 8. That to electrify a body, the natural or proportionate quantity of this fluid must either be augmented or lesscned in that body, and that the positive state consists in an accumulation or excess of electric fluid; and the negative state in a diminution or deficiency of natural quantity.

Let us now proceed to examine separately the different assertions comprehended in the above propositions.

The first proposition comprises three positions respecting the phanomena of electricity, which are not immediately obvious : that they are imputable to one fluid, elastic, and universally diffused. Besides the want of simplicity which characterizes the hypothesis of two fluids, it does not appear to me that any advantage is obtained by it, or that the most perplexing facts are more satisfactorily explained. Two fluids existing in chemical combination could not so asily be separated by causes strictly mechanical : the mere 


\section{of Electricity.}

act of breaking a stick of sealing-wax will produce the two contrary electricities in the two contiguous extremities: it two different substances be rubbed together when insulated, unless the conducting powers of these substances be precisely similar, they will exhibit opposite signs of electricity: the mere contact between two bodies in different states produces an apparent equilibrium, and each ceases to be characterized by any peculiar properties.-Another circumstance which renders the theory of two fluids improbable is, that the quality produced depends not only on the nature of the electric, but on that of the rubber. Those electrics which with some rubbers produce positive, with others produce negative electricity; and almost every elcctric may be made to produce, at pleasure, either positive or negative electricity by the adaptation of proper rubbers. The visible electric atmosphere inay be adduced, as another proof, in favour of the homogeneity of the electric fluid. If $a$ ball, at the termination of a brass rod whose upper end is connected with the prime conductor, be inserted in an exhausted receiver at a sufficient distance from another ball to prevent a spark from passing between them, the upper ball will have a lucid atmosphere extending itself towards the lower ball, while the latter is destitute of any such appearance. If the upper ball be kept negatively electrified by connecting it with the rubber instead of the prime conductor, the effects will be reversed, and the lower ball distinguished by a lucid atmosphere: thus we have an ocular demonstration of the unity of the fluid; for, if there were two fluids, both should have atmospheres : under these various considerations I think we may be justified in ascribing all electrical appearances to the action of a single fluid.

With respect to the elasticity of this fluid, I much doubt whether it is susceptible of proof: as, however, its elasticity is inferred from its repulsive property, it will come under our notice in the next proposition.

The universal diffusion of this fluid may be presumed from our experience: no place has yet been found where, by the usual means of excitation, electricity cannot be obtained; and no reason can be assigned for any partial or local confinement when moisture and other conductors are at hand to convey it over the whole earth. It will on the present occasion be superfluous to examine the identity of lightning and electricity : it will be sufficient to observe that, by the proper management of the electrical kite, it may at all times be collected from the atmosphere. 
The second proposition contains two positions: the attraction of this fluid to other matter, and the repulsive action between its particles. That excited electrics will influence light bodies at a considerable distance, by attracting such towards them, is a fact too common to he controverted; this property of attraction does not appear to be the result of any afinnity between the electric fluid and matter in general, but to proceed from its tendency to equilibrium, and its disposition or power to make use of other substances as common carriers to restore it ; for light substances insulated cannot act in this capacity, and will not be attracted by the conductor.

The repulsive action of the particles of the electric fluid between themiselyes is a question involved in considerable difficulty : the experiments in an exhausted receiver do not indicate any analogy to air or other elastic fluids; for, instead of spreading wider and evincing its elasticity in proportion as the resistance is diminished, the fluid passes in an uninterrupted stream. There are, however, other circumstances which favour a repulsive quality, Thus, light bodies after they become saturated are driven off : if a conductor be brought near an excited cylinder, yet too distant to receive a spark, and an index be placed at each end and in the middle, the near end will be found negative, the remote end positive, and the middle neuter, - proving that a portion of elcctric matter has been driven off, by the action of the excited cylinder, from the nearer to the remoter end; and if a conducting body be presented to the remoter end a spark may be obtained, and on removing the cylinder the whole conductor will be found in a minus or negative state: this repulsive quality is, too, much more subtile than the fluid, and can act like gravitation, through substances which the fluid itself is unable to penetrate.

The repulsion between two pith balls negatively electrified has received many mysterious solutions, none of which, as far as I am acquainted, are at all satisfactory. Without entering into any obscure inquiry about repulsive qualities, may we not refer the divergence of two pith balls, both in cases of positive and negative electricity, to one simple and general principle of attraction? When two pith balls are artificially surcharged with the electric fluid, its endeavour to escape, or its attraction to the surrounding particles floating in the almospherc, would impel the balls to expose the utmost extent of their surface to discharge the superfluous. quantity; and as the most contiguous particles become saturated, 
turated, the balls will diverge, to find fresh particles capable of relieving them, in exact proportion to the degree of their chárge. The same reasoning in an inverted order applies to the negative divergency : the particles immediately contiguous are deprived of their natural share of the electric fluid to restore the equilibrium; and in proportion as these are insufficient to supply the demand, the balls will diverge to obtain it from the next and succeeding ranges of particles. The air is probably a very good electric; and as no actual and continuous communication subsists between the heterogeneous conducting particles floating in the atmosphere, the transmission of the electric fluid to and from the balls, by a conveyance between such conducting but insulated substances, must be too slow and gradual to prevent the divergency alluded to. This hypothesis seems (I mean to myself) both simple and probable: I have endeavoured to illustrate by a figure the detail of this diver. gency.

Let A, B, (fig. 1. Plate III.) represent two pith balls suspended from a point $\mathrm{C}$ by the threads $\mathrm{AFC}, \mathrm{BGC}$, and let the semicircles concentric to each represent particles floating in the atmosphere: the mutual attraction between these particles and the electric fluid contained in the balls $A, B$, when positively electrified, will draw the ball $A$ from the ball $B$ towards $a$ in the line $\mathrm{AD}$; and, when $a$ particles are saturated, to $b, \dot{c}, d, e, f, g, h$, successively in the ratio of the charge till the redundant quantity is discharged, or, as may be supposed the common case, till the powers of attraction and gravitation are balanced, and the balls rest in equilibrio. In the same manner and upon the same principles B will recede to $P$, and both balls will cease to recede whenever their gravity balances the attractive power between the fluid and the atmosphere: in the same manner, in the case of negative electricity both balls require an additional portion, and, unable to obtain a sufficient quantity from $a, i$, traverse successively to $h, p$, till the equilibrium of the fluid is restored, or a balance produced between the attractive and gravitating powers.

The third proposition respects the inaction of the electric fluid in a state of uniform diffusion, and the facility. with which its natural equilibrium is destroyed. The first position is supported by the general analogy of fluids; all of which have a tendency to diffuse themselves in confor mity to some general laws, and at a certain period become stationary, producing no cognizable effects. We hare wery reason to believe that the electric fluid, as well as ca- 
Phito.Mag.PL.II. Vol XIII.

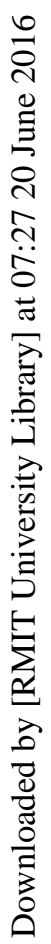
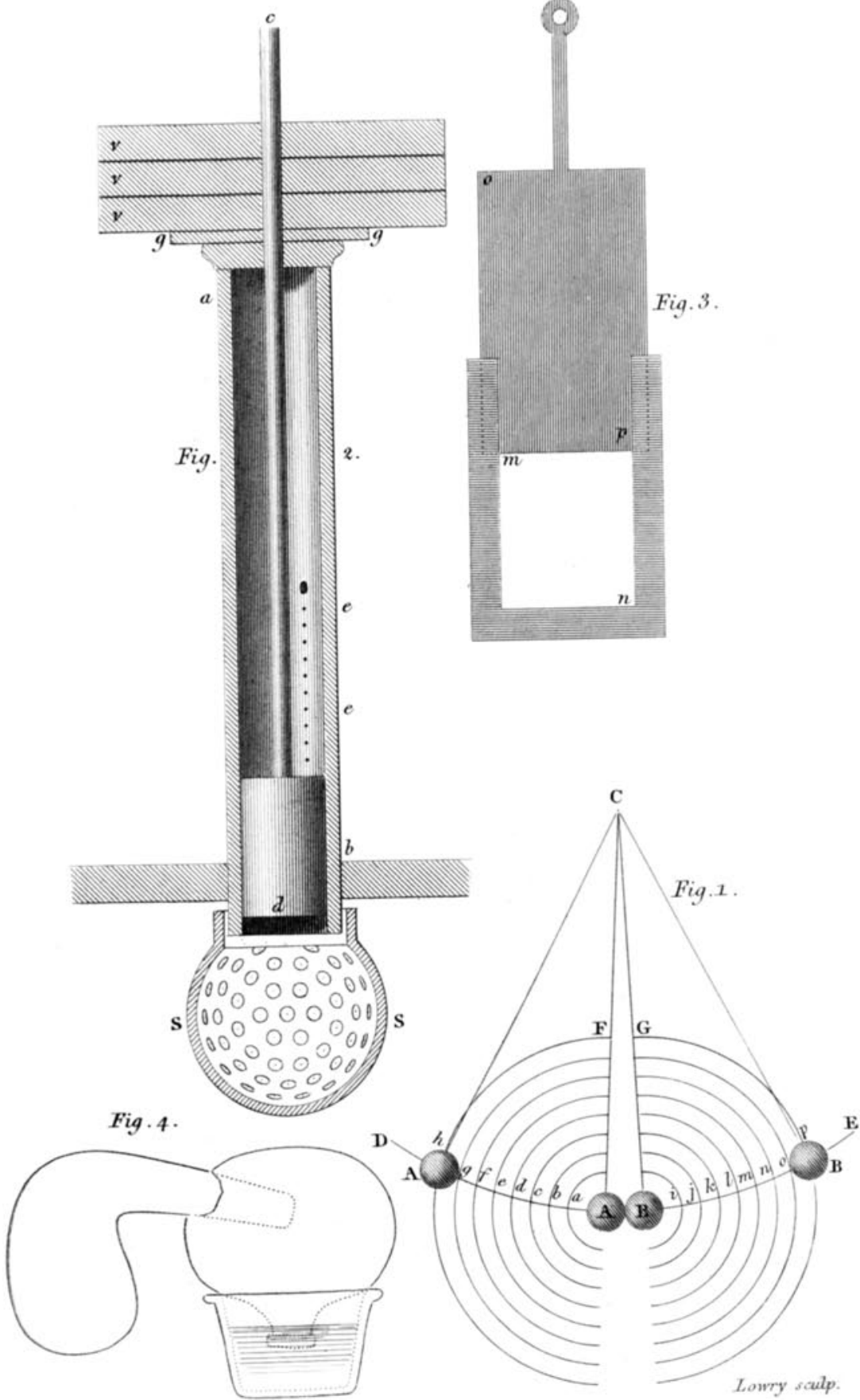
loric, is always present in greater or smaller quantities in the composition of bodies, and we have a right to conclude that when its existence is not manifested by its action it must be in a comparative state, at least, of rest and uniform diffusion, since otherwise its passage would be indicated by external signs or sensations.

The facility with which the cquilibrium is destroyed is very striking : the fracture of sealing-wax, the fall of metallic powders, the mere operation of pressure, are sufficient for this purpose. Mr. Axpinus pressed two plates of glass close together:- when separated and insulated, each acquired a strong electricity, one positive, the other negative; and upon reunion, the electricity of both disappeared: it is obvious that these modes are inferior sorts of excitation; but it is difficult, if not impossible, to offer any solution how excitation produces these effects : the means seem to point out a cause merely mechanical, but the presence of oxygen for some reason sems from experiment to be requisite for their production, It is remarkable that heat destroys the power of excitation, and dry cold augments it.

The fourth proposition is a very important one, and upon which a large proportion of electrical science depends-I mean the distinction between conductors and electrics-in which it is assumed, that in conducting substances the electric fluid moves without obstruction; and in electrics has a very slow and difficult, if any, passage. When we speak hypothetically of conductors and electrics, we suppose them to be perfect in their kind, but practically we are ignorant of any such perfection. In metals which approach the nearest to excellence, as conducting substances, there is often a rery obvious resistance to the passage of the fluid, which is particularly remarkable in the destruction of small wires by the charge of a battery, and the heating of their substance even to rediess and fusion; though the most accurate experiments have been hitherto insufficient to detect any delay of motion by such resistance, or to perceive the lapise of any the loast time during its passage for scveral miles. It has becn much controverted whether the fluid is conveyed alorig the surface or through the substance of cons ductors; but it does not appear to be a point of much consequence, or which at all affects the consistency of the theory. If a wire be coated with some electric substance, such as wax, resin, \&c. it will be found to conduct a charge with as much facility as before; and hence it is inferred that the fluid must pass through the substance of the wire; 
this proof can hardly be deemed conclusive, since it is, at least, doubtful whether the wire and its coating ought to be considered as in actual contact; and if not so, a fluid so extremely subtile might easily pass between them. That the fluid may be forced through the substance of wire is more susceptible of proof from the instances of fusion; but that its tendency is superficial may be inferred from the superior strength of sparks derived from conductors of large surface, extended in length in preference to breadth, when compared with solid conductors:-in short, it is found that the prime conductor of an electrical machine is equally, if not more, effectual when hollow than when solid. In some experiments made by Dr. Priestley, the excoriation of metallic chains resulting from a strong discharge also denotes some determination towards the surface.

If a perfect electric were in our possession, this hypothesis requires us to conceive of it as absolutely impermeable to the electric fluid: but as the qualities of conducting and non-conducting substances coalesce sometimes to a very extraordinary degree, even in glass, which we consider the best electric-I must state that I mean by impermeability, that power of preventing the escape of the fluid which is pecujiar to electrics, which power is ascribed to the great difficulty experienced by the electric fluid in obtaining admission into the pores of such bodies, and the extreme slowness of its progressive motion over their surface or through their substance. This power of confining the fluid is proved by the charge of a Leyden phial, by the well-known in. stances of insulation, and by the durability of electrical properties. Mr. Henley (Phíl. Trans. vol. lxvii,) mentions a simall bottle which retained its electricity for seventy days after charging, and remained during that time in an open cupboard: he had a cylinder variable in the duration of its electricity: once, after excitation, it showed strong signs of elcctricity for thirty-three days : means were repeatedly and successfully resorted to, to remove these appearances; but after a short pause they constantly returned without fresh excitation, alternately became stronger and weaker, vanished and returned without any visible cause : he observed that the electricity was generally weak with a fire in the room, or the door open; during a northerly wind vigorous :- the cylinder did not uniformly retain this power; it would often lose all signs of electricity in 12 hours after excitation; at other times it would remain a fortnight.

The different results of communicating electricity to conductors, or electrics, afford another proof of the difficult 
passage the last-mentioned bodies afford to this fluid: in the first case, it finds an easy passage to any conducting substance presented at a convenient distance, and becomies immediately' discharged; but in the latter case, it acquires any electricity with considerable diffeulty, and, in order to induce it, must be touched several times and in different parts by an electrified body. A curious experiment of prosfessor Lichtenberg, of Göttingen, deserves to be cited upon this occasion (Cavallo, 72): he first excited an electric plate, upon which he placed some metallic body of a convenient shape, and to this he communicated an electricity contrary to the one excited : then removing the métallic body by means of an electric, he shook some finely powdered resin over the electric plate, which fell over those parts only which had been in contact with the metallic body, forming radrated appearances. This description accords with a plate excited negatively, and a body positively electrified : but if the electricities ate changed, the circumstances will be reversed also, and the powdered resin instead of seeking those parts touched by the metallic body will obviously avoid them. - At first sight, no reason appeared for this variation, since both electricities attract an unelectrified body; but, upon more accurate examination, Mr. Cavallo found that the mere action of falling produced a degree of excitation in the powdered resin, which of course became negatively electrified, and could in that state be attracted only by the contrary electricity. Thus, in the first instance, where the plate was negatively electrified and the parts in contact with the metal positive, the powder also in a negative state attached itself to the positive:-in the latter instance, the plate being positive, and the parts in contact negative, the powder also negative would attach itself to the plate, and avoid those parts endued with an electricity similar to its own.

Thus far the path we have trodden does not seem encumbéred with any serious difficulties, but the' observed phænomena require an addition to this hypothesis which is not very easily explicable : in charging a Leyden phial it is obvious, from various experiments, that while one side is receiving the other is emitting: Let a phiat be insulated; and the knob of a second phisl placed at a short distance from its external coating; every spark from the primie conductor to the knob of the first phial will be followed regularly by another spark from its outside coating to the knob. of the second phial, having to the senses all the appearance of a free passage through the glass: but if there were a 
free passage there could be no change, and on the contrary, both phials are found charged; and upon this principle a battery is easily construeted : hence it becomes necessary to assume that electrics contain a large and equal quantity of the electric fluid at all times; that no real accumulation of quantity can take place; but that by affording an opportunity to one side for the escape of this fluid, it is possible to transfer an equal quantity to the other, while the deficiency is balanced by an occult principle of repulsion.

It is certainly very difficult to imagine the existence of a substance capable of yielding a large supply of a peculiar fluid, and into which an additional quantity may be poured on one side while it is abstracted from the other, when, at the same time, it refuses a passage to this fluid through its pores : this, however, is presumed to be the case in electricity. Dr. Franklin once imagined that, in the process of cooling, the middle of a glass plate or jar might become condensed, and its particles so much concentrated, that, while it admitted a circulation of clectric fluid on its surface, it refused it through its substance, Dr. Franklin as usual reduced his conjecture to experiment, by grinding a thick glass plate away beyond the middle, and found that it received a charge with as much facility as before, and immediately acknowledged the fallacy of this opinion. I should feel exceedingly gratified to affard the society some light upon this curious circumstance; but as my own conceptions are involved in profound obscurity, it would be a yain and fruitless attempt to offer a fanciful solution unsupported by experiment or by probability.

The division between the two species of electrics is so fully detailed in the body of the fifth proposition, that it will be unnecessary to support it by any other consideration than an appeal to facts which are generally known. The construction of Mr. Nairne's machine is an ingenious exemplification of its truth; but with respect to the reason which determines these bodies in one instance to receive from, and in other circumstances to yield to, the rubber a supply of electric fluid, we pretend not to assign any. We have examined in the first proposition the presumption which these phænomena afford of the existence of two fluids, and endeavoured to show that such presumption was overthrown by the possibility of producing either negative or positive electricity by the adaptation of proper rubbers. The following table of excitation is extracted from Encyclopcedia Britannica. 


\begin{tabular}{|c|c|c|}
\hline \multirow{4}{*}{$\begin{array}{c}\text { Electrical Substanies } \\
\text { Back of a cat } \\
\text { Glass-smooth } \\
\text { rough } \\
\text { ditto }\end{array}$} & $\begin{array}{c}\text { Rubber. } \\
\text { Fvery }\end{array}$ & \\
\hline & Ditto - & \\
\hline & Silk, sulphur, or metals & \\
\hline & Woollens, paper, wax, hand & \\
\hline Tourmalin - & Amber or air blown upon it & pos. \\
\hline Ditto & $\mathrm{Hz}$ & neg. \\
\hline Hareskin & Is, silk, leather, hand & \\
\hline Ditto & Fine furs - & neg \\
\hline Silk-black & -wax & - \\
\hline white & or cloth, metals & neg \\
\hline & skins, hand - & neg \\
\hline Sealing-wax & Metals & pos. \\
\hline & , hand, woollen & \\
\hline Dake & - & neg. \\
\hline
\end{tabular}

The sixth proposition comprises another material source of electrical knowledge. It states, in the first place, that an excited electric is capable of communicating, by contact or by such proximity as shall permit the free passage of the clectric fluid through the air, an electricity producing upon other bodies precisely the same effects as such excited electric. From this principle is derived the utility of what is called the prime conductor of an electrical machine. This conductor receives, and retains by its insulation, the electric fluid from the excited cylinder, which by this means we have the advantage of obtaining in a more powerful and concentrated state, since by its facility of transmission over the whole surface of such conductor the quantity collected from its various points, on presenting to it another conducting substance, passes off in a single spark, not in minute portions as it was received. This proposition states in the second place, that an excited electric, whose position is such with respect to another body that no spark or other passage of the fluid can take place, will induce upon that body an opposite state of electricity. If an excited tabe be brought near any substance communicating with the ground (but prepared for insulation), this substance when insulated will be found to indicate the negative state of electricity: if, on the contrary, an excited stick of sealing-wax be presented, the positive state will be induced. This circumstance appears to be owing to the repulsive qualities imputed to the electric fluid, so often noticed in the course of our inquiry: the fluid in the excited tube is supposed to repel 
a quantity of the fluid residing in the substance to which it is presented, and to drive it off into the earth, in the same manner as the fluid in an insulated conductor is repelled from the nearest to the remotest end by the action of a machine, as we have attempted to prove under the second proposition : in this situation the substance mentioned will have less than its natural share, and of course indicate negative electricity. If we reverse the picture, the excited wax, by its opposite qualities, enables the substance to receive from the earth an additional quantity, which under insulation appears in the form of positive electricity.

The seventh proposition assumes an universal and uniform distinction between the two states of electricity. If no means are discoverable by which these states can be ascertained, it is sufficiently obvious that all reasoning respecting their particular situations and circumstances must he vague and nugatory: the certainty and facility of this distinction is an essential prop to the whole theory; let u therefore examine evidence. The proofs of this distinction are referable to two classes: one derived from the appearances of electric light; the other from the phænomena of attraction and repulsion. If a point be presented to the insulated rubber of a machine, which by Proposition 5. receives the fluid from such point, a diverging luminous stream will become apparent, which resembles a pencil of rays centring at the point, and darting through the air towards the rubber with a crackling noise, conformably to the expectations we should form of the emission of a fuid resisted equally in its motion by the surrounding atmosphere: but if the needle be transferred in contact with the rubber, its point outwards, which by Proposition 5 . then becomes the recipient instead of emitting the electric fluid, the appearance will be changed: when the fluid is collected from the circumjacent air towards a point, it is natural to conceive it slowly and invisibly percolating from all parts in an equal proportion, till it approaches sufficiently near to break through the intermediate space ; and as this space will be equal on every side, the negative electricity will become visible in the form of a steady, luminous globule on the point, accompanied. with little noise: and this is consonant with experience. The different effects of the two electricities may be advantageously observed by receiving the stream upon the flat side of a piece of paper: a strong plus stream forms a beautiful star about four inches in diameter, consisting of very distinct radii not ramified; the minus stream forms no star, while many pointed brushes centre towards the paper (Cavallo), 
vallo). The appearances in an exhausted receiver; men tioned under Proposition 1. may be adduced as additional proofs. Mr. Cavallo mentions a curious though delicaté experiment as a further corroboration: After moistening the outside of a small phial he charged it at the prime conductor, and while the machine is acting a beautifut brush becomes visible, turning downwards towards the outside coating: if the outside be charged positive, the brush will appear directing its course inwards. The variation in the ensations of receiving a spark affords another collateral testimony to these distinctions, the negative sparks being much more pungent than the positive. The repulsion of two pith balls, or gold leaf, connected with the known property of certain substances to produce on excitation the same electrical quality, affords another and a more delicate and useful means of detecting minuter portions. If an electrometer be brought into contact with any electrified body, the balls or leaf will immediately separate; but we wish to ascertain with which electricity : upon exciting a piece of sealingwax and presenting it to the instrument, its divergency will either increase or diminish : if it increases, it may be concluded similar to that of the excited substance; if it converges, the contrary. If you are desirous to obtain still more accuracy of examination to determine the quality; electrify two similar electrometers, one with some excited body, the other with the body you wish to examine, till the balls indicate equal degrees of divergency: then bring together the two electrometers : if they repel, their electricity may be deemed similar; if they attract, opposite:

The concurrence therefore of these two modes of examination by electric light and electric attraction and repul. sion, if uniform and invariable, as they are asserted to be; effords a satisfactory criterion of the quality.

We are now arrived at the eighth and last proposition; which states in what the qualities of positive and negative electricity consist, viz. in accumulation and deficiency: It has been objected, and I think with some degree of justice, that this position is wholly hypothetical ; that no direct and unequirocal proof can be adduced; and that the arguments commonly urged in its support are included in what logicians denominate a vicious circle. Thus it is said a body positively electrified will attract another body negatively electrified, because the one is redundant, the other is deficient. But how is this known? They attract each other. Again, in charging a phial, there is as constant a stream of electric ftaid from the outside coating as from the conduetor 
to the inside, whence it follows, that while the outside has too little, the inside has too much. Why so? Because the glass is impermeable. How is that proved? Because in the experiment above recited the fluid is accumulated on one side, while it is abstracted on the other. It is evident that under this representation every argument returns into itself, and is merely a play upon terms. I shall however endeavour to show that this statement is neither perfectly candid nor correct, and that the opinion alluded to is supported by more probability than these objectors are willing to admit.

In many instances we can form conclusions only from the effects. If two basons separated by a mound were filled with water, the pressure on all sides being equal, the mound would be likely to maintain its situation. If we suppose one full and the other enupty, with a slight communication between them, the effort to restore the level would endanger the safety of the mound; and if such mound were destroyed, we should instantly conclude that it was occasioned by an accumalation of water on one side and a deficiency on the other. May we not extend the analogy to the electric fluid? It becomes visible only by the air's resistance to its passage: and if its effects are similar to those of water, may we not impute it to the same cause? By the impervious nature of those substances called electrics we are enabled to produce a change, which by effects similar to those above alluded to induces the conclusion, that they are occasioned by an accumulation of the fluid on one side, and its subsequent efforts to restore an equilibrium. If the fiuid as it entered on one side passed through to the other, no change could be effected in the glass: if the glass plate be too thin, and the charge too high, the fluid will force a passage, leaving a small bole or bur in the glass, sometimes cracking the phial all round, and in either case incapacitating it from receiving another charge. It is singular, in the use of resin as a cement to unite the coating and the glass, the phial will not receive the least charge without forcing such a passage.

The easy solution of the phænomena of the Leyden phial on the Franklinian hypothesis has materially contributed to: its reputation. Dr. Franklin proved experimentally that when a phial is charged, one side has lost exactly what the other has acquired : taking a charged phial, he observed, that when he afforded the fluid on the positive side an opportunity to escape, the other side became disposed to receive, and would attract any light body: by insulating his rubber 


\section{9}

On the Franklinian Theory of Electricity.

he found that the phial would not receive a charge, because no fluid could be collected; and by insulating the phial he found the same result, because no opportunity of eseape was afforded to the fluid on the outside; but by forming a communication between the inside and outside coatings the phial was charged with ease : in this case it appeared evident that the fluid residing in the outside had been transferred by the action of the machine to the inside : thus it appears that positive and negative electricity are inseparable, have a constant tendency to produce and preserve each other, and the increase or decrease of power on either surface of a plate of glass must be regulated by the increase or decrease of the contrary power on the opposite side. Inf charging positively no gradual addition of electric matter can be made to one side without a proper conveyance for an equal quantity to pass off on the other side, and in its gradual discharge none can be taken from the positive side without affording the negative side an opportunity of obtaining an equal quantity. The experiments of $\mathrm{Mr}$. Brookes have been supposed to militate against this opinion; but they seem more properly to confirm it, allowing some degree of limitation to the general proposition : he found on charging an insulated phial, by means of a pointed wire, that in the act of charging both sides indicated positive electricity; by the theory the electric fluid is driven off from the external surface by the repulsive action of the positive electricity on the internal side of the phial, and by the confinement of insulation will be constrained to pass gradually through the point, of course producing the effect of accumulation. You will probably recollect, that during the last sessions your experimental committee repeated these experiments with some additional circumstances; and you will remember, that when the phial was not insulated the fluid seemed to pass off instantly; and the outside, even during the act of charging, always indicated the negative electricity. The most serious objection is derived from the difficulty of conceiving how a fluid incapable of percolating the pores of glass can act through the same pores by a peculiar occult repulsive quality: but when we consider the mysterious qualities of gravitation, of magnetism, and even of fluids, whose disposition to rise to the same level is equally unaccountable, we shall feel obliged to acknowledge that this quality affords no rational presumption against the truth of the theory. After all, whatever judgment we form of the general principle, its application in various instances will be insufficient to explain the observed phænomenar 
Mr. Cavallo has candidly acknowledged the difficulty of reconciling various properties of charged electrics with any received theory. Where, for instance, does the charge reside? Not in the coating, as may satisfactorily be shown : if in the glass, and the fluid can penetrate any the smallest portion, a glass might be made so thin that the fluid would freely pervade its substancc; but a glass ball $\frac{1}{60} \mathrm{t}^{\text {th }}$ of an inch thick will receive a powerful charge. The hypothesis still remains incumbered with numerous difficulties; and it must be left to future investigation to determine whether it shall be wholly rejected, or whether subsequent discoveries may enable us to apply the foregoing principles with more certainty and success.

XIV. On the Motion of Bodies affected by Friction. By the Rev. Samuel Vince, A. M. of Cambridge. Communicated by Anthony Shepherd, D.D. F.R.S. Plumian Professor of Astronomy and Experimental Philosophy at Cambridge. Read November 25, 3784.

[Concluded from p. $5_{8 .}$ ]

PROPOSITION II.

LET the body be projected on an horizontal plane LM (fig. 3.) with a given velocity, to determine the space through which the body will move lefore it stops, or before its motion becomes uniform.

CASE I.-1. Suppose the body to have no rotatory motion when it begins to move; and let $a=$ the velocity of projection per second measured in feet, and let the retarding force of the friction of the body measured by the velocity of the body which it can destroy in one second of time, be determined by experiment and called $\mathrm{F}$, and let $x$ be the space through which the body would move by the time its motion was ali destroved when projected with the velocity $\mathrm{a}$, and retarded by a force $\mathrm{F}$; then, from the principles of uniformly retarded motion, $x=\frac{a^{2}}{2 \mathrm{~F}}$, and if $t=$ time of des scribing that space, we have $t=\frac{n}{\mathrm{~F}}$, and hence the space described in the first second of time $=\frac{2 a-F}{2}$. Now it is manifest that when the rotatory motion of the body about its axis is equal to its progressive motion, the point $a$ will be carried backwards by the former motion as much as it is

VoI. XVII. No. 66. 